\title{
Evaluation of genotype by environment interactions on milk production traits of Holstein cows in southern Brazil
}

\author{
Raphael Patrick Moreira', Luis Fernando Batista Pinto ${ }^{2}$, Altair Antônio Valloto ${ }^{3}$, and Victor Breno Pedrosa ${ }^{1, *}$
}

* Corresponding Author: Victor Breno Pedrosa Tel: +55-42-32203081, Fax: +55-42-32203072,

E-mail: vbpedrosa@uepg.br

1 Department of Animal Science, Ponta Grossa State University, Ponta Grossa, PR, 84030-900, Brazil

2 Department of Animal Science, Federal University of Bahia, Salvador, BA, 40170-115, Brazil

${ }^{3}$ Paraná Holstein Breeders Association - APCBRH, Rua Professor Francisco Dranka, Curitiba, PR, 81200-404, Brazil

ORCID

Raphael Patrick Moreira

https://orcid.org/0000-0001-9221-7108

Luis Fernando Batista Pinto

https://orcid.org/0000-0002-0831-3293

Altair Antônio Valloto

https://orcid.org/0000-0001-8956-0685

Victor Breno Pedrosa

https://orcid.org/0000-0001-8966-2227

Submitted Feb 27, 2018; Revised May 11, 2018; Accepted Jul 16, 2018
Objective: This study assessed the possible existence of genotype by environment interactions for milk, fat and protein yields in Holstein cattle raised in one of the most important milk production basins in Brazil.

Methods: Changes in the genetic parameters and breeding values were evaluated for 57,967 animals from three distinct regions of southern Brazil, divided according to differences in climate. The genotype by environment interaction was determined by genetic correlations between regions, estimated by the restricted maximum likelihood, considering the animal model. Bull rankings were investigated to verify the ratio of coincident selected animals between regions for each trait.

Results: The estimates of heritability coefficients were similar between two regions, but were lower in the third evaluated area, for all traits. Genetic correlations between regions were high, ranging from 0.91 to 0.99 for milk, fat and protein yields, representing the absence of a genotype by environment interaction for productive traits. The percentage of selection error between regions for the top $10 \%$ of animals ranged from $0.88 \%$ to $2.07 \%$ for milk yield, $0.99 \%$ to $2.46 \%$ for fat yield and $0.59 \%$ to $3.15 \%$ for protein yield.

Conclusion: A slight change in genotype between areas was expected since no significant genotype by environment interactions were identified, facilitating the process of selecting Holstein cattle in southern Brazil.

Keywords: Dairy Cattle; Environmental Effects; Genetic Evaluation; Milk Yield; Milk Solids

\section{INTRODUCTION}

Reproductive biotechnology has resulted in the extensive and global distribution of genetic material from animals with high productive potential. For this reason, genotypes that are chosen from areas dissimilar to the region in which they are to be introduced may not satisfy breeder expectations. This aspect may be related to the genotype lacking an adaptation to the territory in which it is introduced; this in turn will affect the genotype by reducing the expression of its maximum productive potential [1]. The genotypexenvironment interaction (GEI) has several implications that may significantly affect dairy production, including factors responsible for the production of milk, fat and protein. Apart from this, the individual breeding values can be affected, finally culminating in a reclassification of the breeding rankings [2].

In Brazil, a major proportion of milk production comes from the Holstein breed [3]. However, very few studies have focused on productive traits in response to the variety of climates prevailing in the different regions of the country. Most temperate countries, particularly the United States, Canada and Netherlands, which have preferred the Holstein breed for a long time, are well-known as big exporters of semen from the breed [4]. They are now expanding their markets, making successful entries into the tropical and subtropical zones of the world, including Brazil. It therefore becomes crucial to assess whether the imported genetic material 
will meet the performance expected by breeders in various environmental contexts and emphasises the significance of GEI studies in dairy cattle.

The Paraná Basin in southern Brazil is well-known for having the highest dairy productivity per animal in the country. However, it is characterised by sharp climatic diversity, with some regions experiencing temperate climate conditions, while others have subtropical climate [5]. Therefore, such climatic differentiations occurring within the state do exert some influence that can alter the traits of interest to some degree. Furthermore, in Brazil, findings regarding the presence of GEI in the Holstein breed are meagre, with reports being available but limited only in terms of milk production [6] and not fat and protein production. Therefore, the present study focused on assessing the influence of the GEI on the production of milk, fat and protein in Holstein herds in Paraná, Brazil.

\section{MATERIALS AND METHODS}

Data on $305 \mathrm{~d}$ milk yield (MY), fat yield (FY), and protein yields (PY) recorded from 57,967 primiparous cows in 375 herds were taken from the database of the Holstein Association in Paraná, Brazil, considering the years between 1990 and 2015. A pedigree file containing the animal's identification, sire and dam was used, totalling 79,387 animals in the relationship matrix.

The effects included in the model were the fixed effects of contemporary group and the cow age at calving as a covariate (linear and quadratic), beyond the random additive genetic effect. The contemporary groups were created considering the interactions of herd-year-season, with four seasons of the partum being considered, i.e., December to February, March to May, June to August, and September to November. The data were checked and records that included errors, insufficient information, animals of unknown parentage, progenies of bulls which only pertain to one herd, and contemporary groups containing fewer than three animals were removed.

The state of Paraná in southern Brazil is situated between $22^{\circ} 30^{\prime} 58^{\prime \prime}$ and $26^{\circ} 43^{\prime} 00^{\prime \prime}$ south latitude and $48^{\circ} 05^{\prime} 37^{\prime \prime}$ and $54^{\circ} 37^{\prime} 08^{\prime \prime}$ west longitude and extends across $199,307 \mathrm{~km}^{2}$. Based on the climatic classification of the Secretariat of Agriculture of the State of Paraná, Brazil [7], the following different regions were easily distinguished: region 1 (R1): mesothermal climate humid and super humid (lacking a dry season, but experiencing severe winter, severe and frequent frost, rainy and mild summers, at altitudes higher than 850 to $900 \mathrm{~m}$ ); region 2 (R2): mesothermal climate with no dry season (harsh winter with average rainfall and some frost, rainy summers and high temperature, altitudes normally below 850 to $900 \mathrm{~m}$ ); region 3 (R3): mesothermal climate with a distinct dry season (hot summers and low occurrence of frost, mostly lower than 850 to $900 \mathrm{~m}$ ).
Multi-trait analyses were performed using the GEI for a group that included the three regions $(\mathrm{R} 1+\mathrm{R} 2+\mathrm{R} 3)$, for each individual trait, considering the same trait in each region as a distinct characteristic. The connectivity between the herds was assured by connecting sires, maintaining only those that produced at least one cow simultaneously, in at least two of the three regions in the study. A total of 1,016 sires were assessed in this study, genetically connected by region as follows: R1 and R2 (951 sires); R1 and R3 (528 sires); R2 and R3 (480 sires); R1, R2, and R3 (471 sires).

In the general matrix format, the model was represented as given: $\mathrm{y}=\mathrm{Xb}+\mathrm{Za}+\mathrm{e}$, where $\mathrm{y}$ is the vector of the analysed trait, $b$ refers to the vector of solutions for the fixed effects containing the contemporary group and covariate of the age at birth, $a$ is the vector of the solutions for the additive genetic random effect, $\mathrm{X}$ and $\mathrm{Z}$ are the incidence matrices for the fixed and additive genetic effects, respectively, and e is the vector of the random residuals. For the multi-trait analysis, regarding the joint analysis of the different regions, the matrix model was explained as given:

$$
\mathrm{Y}=\left[\begin{array}{l}
y_{1} \\
y_{2} \\
y_{3}
\end{array}\right]=\left[\begin{array}{ccc}
X_{1} & 0 & 0 \\
0 & X_{2} & 0 \\
0 & 0 & X_{3}
\end{array}\right] \cdot\left[\begin{array}{l}
\beta_{1} \\
\beta_{2} \\
\beta_{3}
\end{array}\right]+\left[\begin{array}{ccc}
Z_{1} & 0 & 0 \\
0 & Z_{2} & 0 \\
0 & 0 & Z_{3}
\end{array}\right] \cdot\left[\begin{array}{l}
a_{1} \\
a_{2} \\
a_{3}
\end{array}\right]+\left[\begin{array}{l}
e_{1} \\
e_{2} \\
e_{3}
\end{array}\right]
$$

where $\mathrm{y}_{1}$ is the vector of observations of MY, FY, and PY in R1, $\mathrm{y}_{2}$ is the vector of the observations of MY, FY, and PY in R2 and $y_{3}$ is the vector of the observations of MY, FY, and PY in $R 3$, respectively; $X_{1}, X_{2}$, and $X_{3}$, are the fixed effects incidence matrices, contained in vectors $\beta_{1}, \beta_{2}$, and $\beta_{3}$, respectively; $Z_{1}$, $Z_{2}$, and $Z_{3}$ are the incidence matrices of the additive genetic effects contained in vectors $a_{1}, a_{2}$, and $a_{3}$, respectively; $e_{1}, e_{2}$, and $e_{3}$ are the random error vectors associated with vectors $\mathrm{y}_{1}, \mathrm{y}_{2}$, and $\mathrm{y}_{3}, 1,2$ and 3 are the R1, R2, and R3 regions, respectively.

$$
\left[\begin{array}{l}
\alpha \\
e
\end{array}\right] \sim N M V\left(\left[\begin{array}{l}
0 \\
0
\end{array}\right], \quad\left[\begin{array}{ll}
G & 0 \\
0 & R
\end{array}\right]\right)
$$

where the $G$ and $R$ matrices are defined as $G=G 0 \otimes A$ and $R$ $=\mathrm{R} 0 \otimes \mathrm{I}$, respectively; where $\mathrm{G} 0$ refers to the additive genetic covariance matrix of the three regions and $\mathrm{R} 0$ is the residual matrix for the three regions where the animal will be observed.

The presence or absence of the GEI was determined by the genetic correlations between the regions, as explained by Falconer [8]. The variance components and genetic parameters were estimated by the restricted maximum likelihood method using VCE6.0 software according to Groeneveld [9], considering the animal model. The breeding values were obtained using PEST software [10]. Additionally, the breeding values and classification of the bulls were submitted to the Pearson and Spearman correlations, respectively, adopting the CORR procedure [11]. Regarding the bulls, the coincident animals 
between R1, R2, and R3 were established, when $10 \%$ of the bulls with the highest predicted transmission ability (PTA) were chosen for each trait in each location, based on the method employed by Pedrosa et al [12].

\section{RESULTS}

The additive, residual and phenotypic variances are shown in Table 1. Table 2 provides the heritabilities for each region and genetic correlations between each region for the three traits. $\mathrm{R} 2$ revealed equal heritability for MY in relation to R1. For R1 and $\mathrm{R} 2$, the value was 0.21 , and for R3 it was 0.16 . The same was observed for FY, where R1 and R2 showed similar values, with a heritability value of 0.25 and $\mathrm{R} 3$ equal to 0.17 . The PY registered less heritability compared with the other traits, with $\mathrm{R} 3, \mathrm{R} 2$, and $\mathrm{R} 1$ being $0.10,0.16$, and 0.17 , respectively.

The three traits under consideration and among all the regions assessed showed high genetic correlations. For MY, the genetic correlations revealed a value of 0.97 between $\mathrm{R} 2 \times \mathrm{R} 3$, 0.99 between $\mathrm{R} 1 \times \mathrm{R} 3$ and 0.93 between $\mathrm{R} 1 \times \mathrm{R} 2$. In the case of FY the correlations between $\mathrm{R} 2 \times \mathrm{R} 3, \mathrm{R} 1 \times \mathrm{R} 3$, and $\mathrm{R} 1 \times \mathrm{R} 2$ were $0.99,0.94$, and 0.93 , respectively. PY revealed correlations of 0.93 between $\mathrm{R} 2 \times \mathrm{R} 3,0.99$ between $\mathrm{R} 1 \times \mathrm{R} 3$ and 0.91 between $\mathrm{R} 1 \times \mathrm{R} 2$. Table 3 shows the Pearson correlations between the regions for the PTA of the bulls for all studied traits. For the three traits between the regions, all the values were confirmed and found to be close to 1. For MY, the Pearson correlation was the highest between the $\mathrm{R} 1 \times \mathrm{R} 3$ regions (1.00), followed by $\mathrm{R} 2 \times \mathrm{R} 3(0.99)$, and $\mathrm{R} 1 \times \mathrm{R} 2(0.99)$. The sequence for FY was $\mathrm{R} 2 \times \mathrm{R} 3$ (1.00), R1×R3 (0.99), and R1×R2 (0.98). For PY, the correlations showed values of $1.00,0.99$ and 0.98 for $\mathrm{R} 2 \times \mathrm{R} 3$, $\mathrm{R} 1 \times \mathrm{R} 3$, and $\mathrm{R} 1 \times \mathrm{R} 2$, respectively. Among bull ranks, the Spearman correlation also revealed high values. The values for MY were $1.00,0.99$, and 0.99 for $\mathrm{R} 1 \times \mathrm{R} 3, \mathrm{R} 2 \times \mathrm{R} 3$, and $\mathrm{R} 1 \times \mathrm{R} 2$, respectively. Relative to $\mathrm{FY}$, the $\mathrm{R} 2 \times \mathrm{R} 3$ regions registering a correlation of 1.00 showed similarity to R1 $\times \mathrm{R} 3$ with 0.99 and $\mathrm{R} 1 \times \mathrm{R} 2$ with 0.98 . For $\mathrm{PY}$, the $\mathrm{R} 1 \times \mathrm{R} 3$ value was 1.00 , while for $\mathrm{R} 2 \times \mathrm{R} 3$ it was 0.99 and $\mathrm{R} 1 \times \mathrm{R} 2$ showed 0.98 .

Table 1. Additive genetic variance $\left(\sigma_{a}^{2}\right)$, residual variance $\left(\sigma_{e}^{2}\right)$ and phenotypic variance $\left(\sigma_{p}^{2}\right)$ for milk yield (MY), fat yield (FY), and protein yield (PY) for Region 1, Region 2, and Region 3

\begin{tabular}{lcccc}
\hline Items & \multicolumn{1}{c}{$\sigma_{a}^{2}$} & $\sigma_{e}^{2}$ & $\sigma_{p}^{2}$ \\
\hline MY & Region 1 & $555,716.51$ & $2,043,254.33$ & $2,598,970.84$ \\
& Region 2 & $504,443.32$ & $1,929,089.12$ & $2,433,532.44$ \\
& Region 3 & $368,608.08$ & $1,952,364.42$ & $2,320,972.50$ \\
FY & Region 1 & 786.91 & $2,386.74$ & $3,173.65$ \\
& Region 2 & 792.87 & $2,345.70$ & $3,138.56$ \\
& Region 3 & 480.05 & $2,363.86$ & $2,843.91$ \\
PY & Region 1 & 380.47 & $1,850.11$ & $2,230.58$ \\
& Region 2 & 363.63 & $1,838.68$ & $2,202.31$ \\
& Region 3 & 211.02 & $1,872.70$ & $2,083.71$ \\
\hline
\end{tabular}

Table 2. Heritability (diagonal) and genetic correlation (above diagonal) for milk yield (MY), fat yield (FY), and protein yield (PY) in Region 1, Region 2, and Region 3

\begin{tabular}{llccc}
\hline Items & & R1 & R2 & R3 \\
\hline MY & Region 1 & 0.21 & 0.93 & 0.99 \\
& Region 2 & - & 0.21 & 0.97 \\
& Region 3 & - & - & 0.16 \\
FY & Region 1 & 0.25 & 0.93 & 0.94 \\
& Region 2 & - & 0.25 & 0.99 \\
& Region 3 & - & - & 0.17 \\
PY & Region 1 & 0.17 & 0.91 & 0.99 \\
& Region 2 & - & 0.16 & 0.93 \\
& Region 3 & - & - & 0.10 \\
\hline
\end{tabular}

Figures 1, 2, and 3 show the PTA dispersions for the three traits in the quadrants established by the truncation points of $10 \%$ of the best bulls. Such a dispersion enabled the identification of selection errors in the regions under investigation. For MY, the PTAs that set the truncation points were 385.44 , 363.32, and 316.17 for R1, R2, and R3, respectively. The points for FY were 14.40 for R1, 13.99 for R2 and 11.04 for R3. PY revealed the truncation points of the PTAs of the bulls from 10.23 to R1, 9.51 to R2 and 7.67 to R3. Thus, from the PTA dispersions, the proportions of the coincident animals between the regions for the traits under study were assessed. On evaluating the proportion of the coincident animals for MY, values of $98.82 \%$ were reported between $\mathrm{R} 2 \times \mathrm{R} 3,99.12 \%$ between $\mathrm{R} 1 \times \mathrm{R} 3$ and $97.93 \%$ between $\mathrm{R} 1 \times \mathrm{R} 2$. For FY, the proportion of the coincident animals was $99.8 \%, 97.84 \%$, and $97.54 \%$ for $\mathrm{R} 2 \times \mathrm{R} 3, \mathrm{R} 1 \times \mathrm{R} 3$, and $\mathrm{R} 1 \times \mathrm{R} 2$, respectively. In the case of $\mathrm{PY}$, the proportions recorded were $97.45 \%$ for $\mathrm{R} 2 \times \mathrm{R} 3,99.41 \%$ for $\mathrm{R} 1 \times \mathrm{R} 3$ and $96.85 \%$ for $\mathrm{R} 1 \times \mathrm{R} 2$.

\section{DISCUSSION}

From the variances gathered for the three traits in the regions under investigation, it was demonstrated that the environmental variance accounted for a major portion of the total variance

Table 3. Pearson correlations (above diagonal) and Spearman correlations (below diagonal) for milk yield (MY), fat yield (FY) and protein yield (PY) in Region 1, Region 2, and Region 3

\begin{tabular}{llccc}
\hline Items & & R1 & R2 & R3 \\
\hline MY & Region 1 & - & 0.99 & 1.00 \\
& Region 2 & 0.99 & - & 0.99 \\
& Region 3 & 1.00 & 0.99 & - \\
FY & Region 1 & - & 0.98 & 0.99 \\
& Region 2 & 0.98 & - & 1.00 \\
& Region 3 & 0.99 & 1.00 & - \\
PY & Region 1 & - & 0.98 & 1.00 \\
& Region 2 & 0.98 & - & 0.99 \\
& Region 3 & 1.00 & 0.99 & - \\
\hline
\end{tabular}



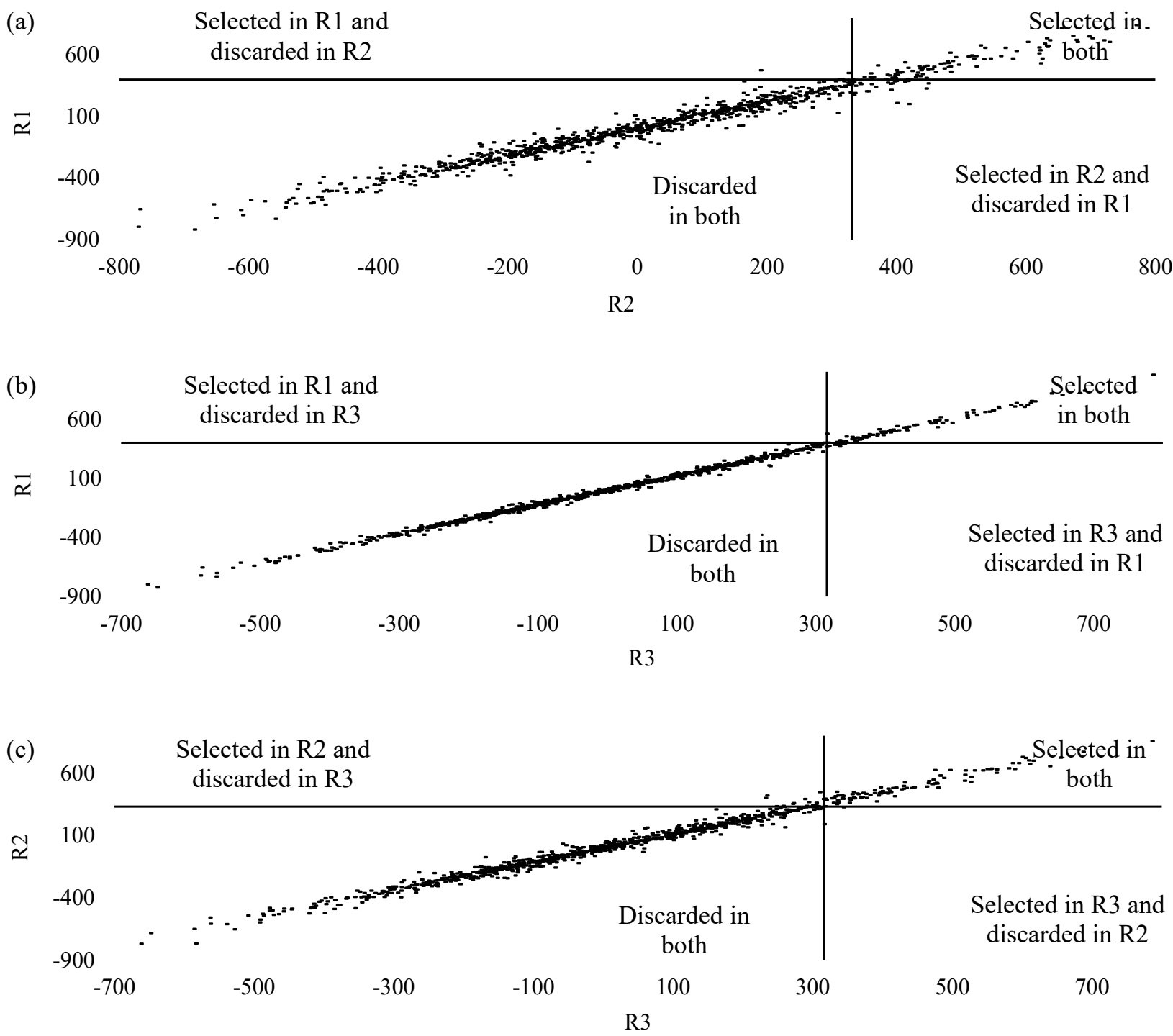

Figure 1. Dispersions of PTAs for milk yield in the quadrants defined by the truncation points of the best $10 \%$ bulls for: (a) R1 (PTA $\geq 385.44$ ) and R2 (PTA $\geq 363.32$ ); (b)

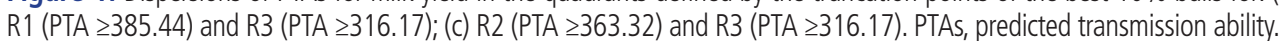

in these traits, causing low to moderate heritabilities, especially evident in R3. Greater estimates of the additive genetic variance for the three traits were shown, based on the regions that revealed more productivity, concurring with the findings of Montaldo et al [13]. In this instance, selection increased the additive genetic variance in the herds, and thus raised the estimate of heritability of the traits over the long term.

The heritability values for MY, FY in R1 and R2 were found to be moderate in magnitude and were similar to those reported by Campos et al [14] in their evaluation of data from Holstein cows in Brazilian herds. Huquet et al [15] also found values of moderate to high heritability (from 0.39 to 0.47 ) for MYs and FYs in their evaluation of Holstein cattle in France. Such high values for heritability recorded in some studies may occur because these herds undergo significant genetic selection in the programs widely adopted in their countries and form adapted genotypes. Additionally, the environmental control practiced in these countries is more intense, utilising more homogeneous production systems and thus minimising the environmental variance. The $\mathrm{R} 3$ was the region that presented the lower heritabilities. Apart from this, the heritability results obtained in all three regions for PY concur with the work of Bernabucci et al [16] and Campos et al [14], i.e. 0.15 and 0.17, respectively. The results of $0.17,0.16$, and 0.10 reported for R1, R2, and R3, respectively, reiterate that PY has low heritability. Considering this, it can be concluded that selection for FY has a tendency to reveal greater genetic gains in smaller generations, as compared to PY.

From the genetic correlations applied in the estimation of the presence of the GEI for MY, the changes in the expression of the genotype between R1 and R3 (0.99) because of environmental differences, are less in relation to the comparative 

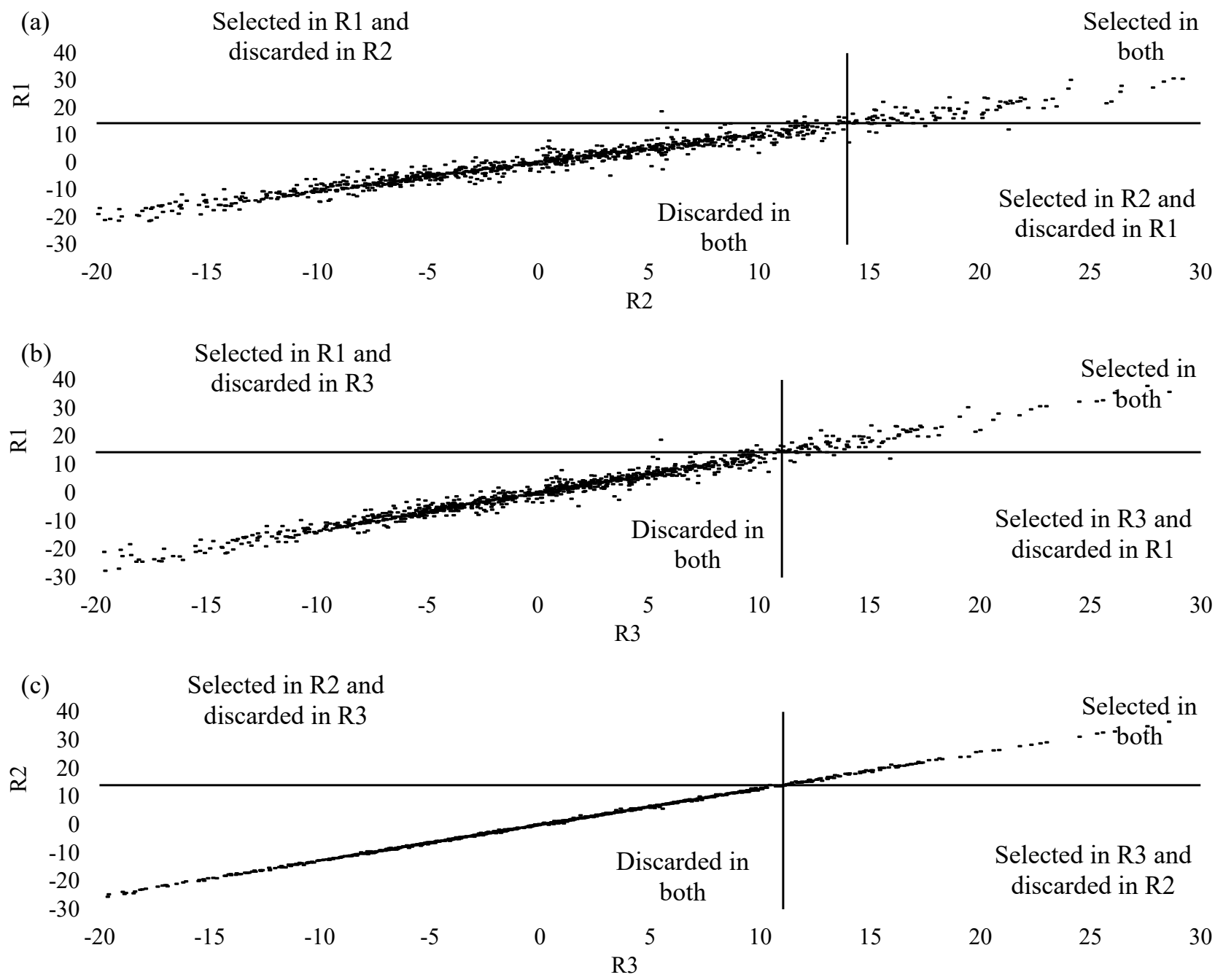

Figure 2. Dispersions of PTAs for fat yield in the quadrants defined by the truncation points of the best $10 \%$ bulls for: (a) R1 (PTA $\geq 14.40$ ) and R2 (PTA $\geq 13.99$ ); (b) R1 $(P T A \geq 14.40)$ and R3 (PTA $\geq 11.04) ;(c)$ R2 (PTA $\geq 13.99) ;$ and R3 (PTA $\geq 11.04)$. PTAs, predicted transmission ability.

among the $(\mathrm{R} 2 \times \mathrm{R} 3=0.97$ and $\mathrm{R} 1 \times \mathrm{R} 2=0.93)$. Robertson et al [17] stated that the presence of the GEI is evident when the coefficients of genetic correlations are below 0.80 . Therefore, no interaction for MY was evident, because all the regions reported values higher than the one mentioned above. Zwald et al [2] highlighted the role of environment as the possible predominant factor in the effect on production, provided that the manifestations of the genetic components are influenced by the variables such as temperature differences between the regions, for example, characterising the presence of environmental genotype interactions between the different regions. However, the absence of any interaction among the regions reveals that factors including temperature, herd size and influence of genetic material from outside were inadequate to bring about significant alterations in the phenotype expression among the regions being investigated.

The results of the genetic correlations for FY revealed the absence of any significant influence of a GEI as its value fell within the range of 0.93 to 0.99 between the regions. It has already been established that fat is one of the constituents that induces greater instability in milk; variability in FY occurs due to several factors. However, the results reiterate that the changes caused by distinctive genetics among the animals was of no significance. According to the investigation of Montaldo et al [13], the interactions between the FY in Canada, the United States and Chile is influenced by climatic and regional differences, which tend to induce a notable GEI for FY, confirming the reported results.

For PY, variations in the genetic correlations among the evaluated regions were observed from 0.91 between R1 and $\mathrm{R} 2$ to 0.99 between $\mathrm{R} 1$ and R3. Therefore, it was accepted that $\mathrm{R} 1$ appeared to show more similarity in the effects to R3 in terms of the expression of this characteristic, relative to R2. However, from the magnitude of the results shown, the environmental influence was insufficient to induce a significant interaction effect. This occurs because, according to Kolmodin 

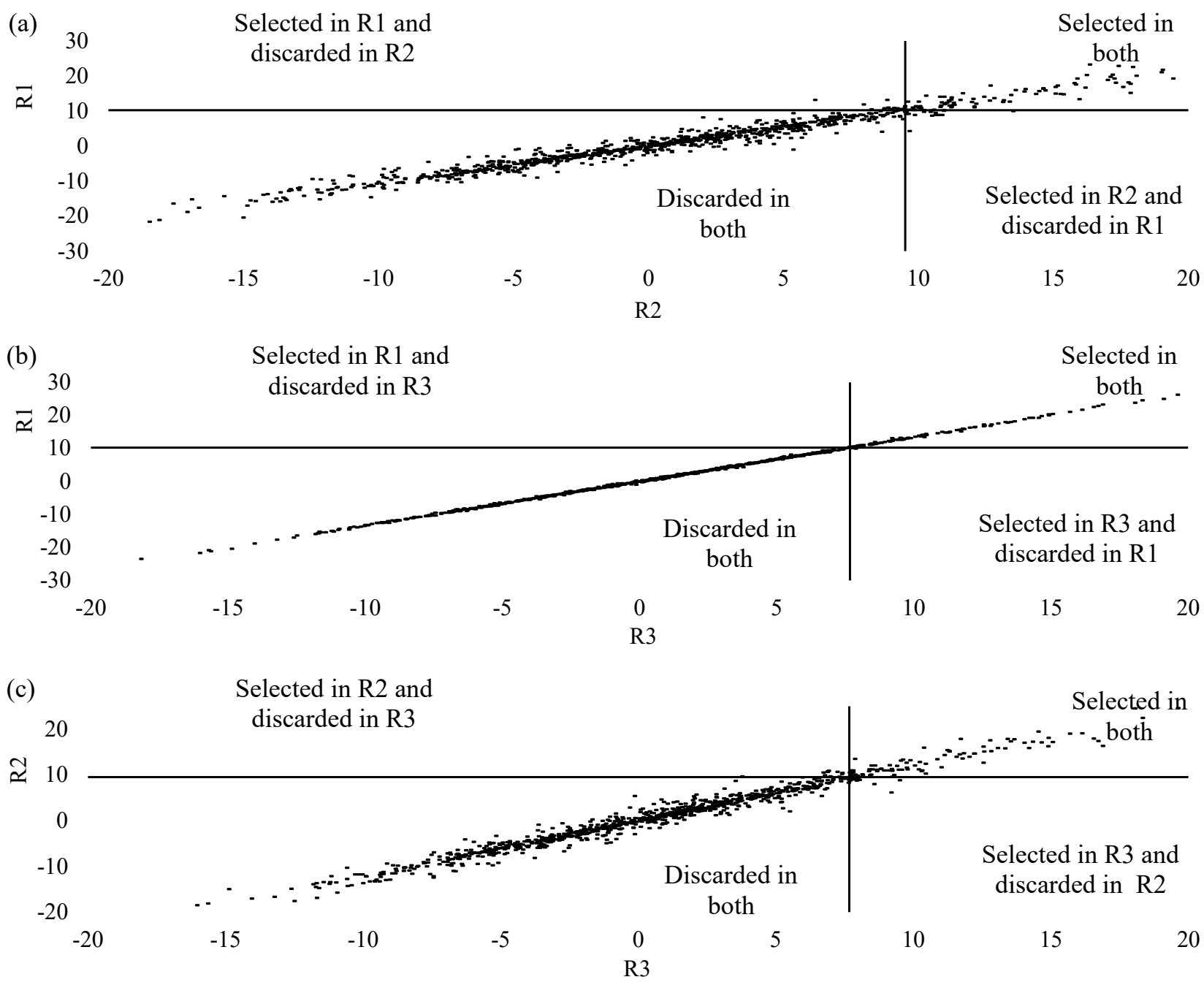

Figure 3. Dispersions of PTAs for protein yield in the quadrants defined by the truncation points of the best $10 \%$ bulls for: (a) R1 (PTA $\geq 10.23$ ) and R2 (PTA $\geq 9.51$ ); (b) R1 (PTA $\geq 10.23$ ) and R3 (PTA $\geq 7.67$ ); and (c) R2 (PTA $\geq 9.51$ ) and R3 (PTA $\geq 7.67)$. PTAs, predicted transmission ability.

et al [18], alterations in the average rainfall exert little or no effect on the PY, reducing the effects of environmental variance on the total component. However, latitudinal differences have been cited in the literature as the principal reason for the alterations in temperature and time of day [19]. Carabaño et al [20] pointed out that temperature can be a determinant factor that influences the interaction on the production of protein in milk. However, in this study, all the regions of the Paraná were situated within the same latitude range $\left(-30^{\circ}\right.$ to $\left.-20^{\circ}\right)$. These factors thus reveal that latitudinal differences between the three regions did not exert a noteworthy effect on the response of this characteristic. Finally, this fact can also justify the lack of any remarkable effect on MY and FY, which showed correlations close to 1 , as mentioned earlier.

The present study relied on Pearson's correlations to confirm the veracity of the genetic correlations and further the understanding of the absence of GEI in the Paraná Basin. The results recorded for MY, FY, and PY revealed only very slight distinctions between the genetic values of the animals from one region to another, because the Pearson correlation ranged from 0.98 to 1.00 for the characteristics, between the three regions. Further, the Spearman correlations for the three traits reiterated that the alterations among the bull ranks was low in magnitude between the regions. The values followed Pearson's standard, ranging from 0.98 to 1.00. Calus and Veerkamp [21] suggested that the GEI might either induce a change in the classifications of the animals, termed reclassification, or reveal only the presence of differences in the breeding values of the animals, without necessitating any classification changes, otherwise termed the scale effect. This emphasises the fact that the animals assessed here showed only slight changes in breeding values between the different regions, with negligible changes in the classification rankings.

Figure 1 shows that the selection error for MY between the regions was in the range of $0.88 \%$ to $2.07 \%$, and thus of no significance. This means that the number of bulls selected in 
one region, when they would be evaluated in another, should not be insignificant. In practice, this confirms the absence of a GEI for MY between the regions, based on the genetic correlations given earlier in Table 2. The best method would be to choose a specific selection program that could include the progenies evaluated in R1 and then the results of PTAs could be extrapolated for the selection of the same animals in the other two regions; then, the percentage of certainty would be around $99.12 \%$ for R3 and $97.93 \%$ for R2.

This claim was also confirmed for fat and protein production. When considering FY, as revealed in Figure 2, the selection error ranged from $0.99 \%$ to $2.46 \%$, and for PY (Figure 3) from $0.59 \%$ to $3.15 \%$. Therefore, for these two characteristics, our confidence in a selection program done in R1 and adopted in the other regions would vary from $96.85 \%$ to $99.41 \%$, showing up as highly reliable. It is also noteworthy that the regions that exhibited genetic correlations of 0.99 , like R1 and R3 for MY, R2 and R3 for FY and R1 and R3 for PY, showed greater uniformity in the bull PTA dispersions.

According to Mulder et al [22], when high genetic correlations are evident between different regions, the highest average genetic gain occurs with only a single selection program, rather than several different programs. The present study supports this assertion because, as previously mentioned, high genetic correlations demonstrate differences of low magnitude in the animal PTAs. Furthermore, as stated above, most of the animals in the Paraná herds were imported from regions experiencing different climatic conditions, which frequently decreased the selection efficiency. Considering these aspects, a cooperative selection program by breeders specifically tailored for such traits would be very acceptable, as it would create animals adapted to these climatic conditions, which could be used by producers in Paraná. It is also the authors' view that such a methodology, besides increasing genetic progress, could also induce very positive results due to the drop in semen price, thus proving to be advantageous to small producers as well, who form a big part of the primary milk chain in the Paraná Basin.

Based on the findings of this study, it is evident that the three climatic regions assessed in the Paraná Basin in Brazil showed no significant GEI for the traits assessed in the Holstein breed. The breeding values of the animals and their classifications revealed no alterations, irrespective of the regions where they were produced. This makes it clear that the genetic predictions concluded in these regions assessed can, without significant bias, be utilised between regions. Additionally, regarding the absence of any influence exerted by the GEI, a genetic selection program alone will be required for the Holstein dairy herd in Paraná, indicating heightened efficiency and lowered additional expenditure for the implementation of development techniques.

\section{CONFLICT OF INTEREST}

We certify that there is no conflict of interest with any financial organization regarding the material discussed in the manuscript.

\section{ACKNOWLEDGMENTS}

The authors thank the Paraná Holstein Breeders Association (APCBRH) for providing the pedigree and phenotypic data. To National Council for Scientific and Technological Development $(\mathrm{CNPq})$, National Council for the Improvement of Higher Education (CAPES) and Araucária Foundation (Fundação Araucária) for granting the scholarships and the funds to develop this research.

\section{REFERENCES}

1. van der Laak M, van Pelt ML, de Jong G, Mulder HA. Genotype by environment interaction for production, somatic cell score, workability, and conformation traits in Ducth Holstein-Friesian cows between farms with or without grazing. J Dairy Sci 2016; 99:4496-503.

2. Zwald NR, Weigel KA, Fikse WF, Rekaya R. Identification of factors that cause genotype by environment interaction between herds of Holstein cattle in seventeen countries. J Dairy Sci 2003; 86:1009-18.

3. Boligon AA, Rorato PRN, Ferreira GBB, et al. Heritability and genetic trend for milk and fat yields in Holstein herds raised in the State of Rio Grande do Sul. R Bras Zootec 2005;34:15128.

4. Pedrosa VB, Valloto AA, Horst JA, Figueiredo AM, Martins AS. Genetic trends in dairy yield of Brazilian Holstein cow. In: Joint Annual Meeting - ADSA/ASAS 2015, 2015 Jul 12-Jul 16; Orlando, FL, USA: American Dairy Science Association; 2015. p. 346.

5. Analysis of the agricultural scenario 2010-2011 - agrometeorology (2010/2011) [Internet]. Curitiba, PR, Brazil: Rural Economy Department; 2010 [cited 2017 May 03]. Available from: http://www.agricultura.pr.gov.br/arquivos/File/deral/ Prognosticos/agrometeorologia_2010_11.pdf

6. Paula MC, Martins EN, Silva LOC, et al. Genotype $\times$ environment interaction for milk yield of Holstein cows among dairy production units in the state of Paraná. Rev Bras Zootec 2009; 38:467-73.

7. Characterization of dairy cattle in the state of Paraná [Internet]. Curitiba, PR, Brazil: Secretary of Agriculture and Supply; 2000 [cited 2015 Nov 10]. Available from: http://www.agricultura. pr.gov.br/arquivos/File/deral/cultura3.pdf

8. Falconer DS. The problem of environment and selection. Am Nat 1952;86:293-8.

9. Groeneveld E, Kovac M, Mielenz N. VCE User's guide and 
reference manual. Version 6.0, Mariensee, Neustadt, Germany: Federal Agricultural Research Center (FAL); 2008.

10. Groeneveld E, Kovac M, Mielenz N. PEST2 User's guide and reference manual. Version 2.0, Mariensee, Neustadt, Germany: Federal Agricultural Research Center (FAL); 2009.

11. Statistical Analysis System. User's guide [CD-ROM]. Version 9.1, Cary, NC, USA: SAS Institute; 2009.

12. Pedrosa VB, Eler JP, Ferraz JB, Groeneveld E. Use of weaning management group as a random effect for a more robust estimation of genetic parameters for post-weaning traits in Nellore cattle. Genet Mol Res 2014;13:7013-21.

13. Montaldo HH, Castillo-Juárez H, Lizana C, et al. Genotypeenvironment interaction between Chile and North America and between Chilean herd environmental categories for milk yield traits in Black and White cattle. Anim Sci Pap Rep 2015; 33:23-33.

14. Campos RV, Cobuci JA, Kem EL, Costa CN, Mcmanus CM. Genetic parameters for linear type traits and milk, fat, and protein production in Holstein cows in Brazil. Asian-Australas J Anim Sci 2015;28:476-84.

15. Huquet B, Leclerc H, Ducrocq V. Modelling and estimation of genotype by environment interactions for production traits in French dairy cattle. Genet Sel Evol 2012;44:35.

16. Bernabucci U, Biffani S, Buggiotti L, et al. The effects of heat stress in Italian Holstein dairy cattle. J Dairy Sci 2014;97:47186.

17. Robertson $A$. The sampling variance of the genetic correlation coefficient. Biometrics 1959;15:469-85.

18. Kolmodin R, Strandberg E, Danell B, Jorjani H. Reaction norms for protein yield and days open in Swedish red and white dairy cattle in relation to various environmental variables. Acta Agric Scand Sect A Anim Sci 2004;54:139-51.

19. Ismael A, Strandberg E, Berglund B, et al. Genotype by environment interaction for the interval from calving to first insemination with regard to calving month and geographic location in Holstein cows in Denmark and Sweden. J Dairy Sci 2016;99: 5498-507.

20. Carabaño MJ, Bachagha K, Ramón M, Díaz C. Modeling heat stress effect on Holstein cows under hot and dry conditions: Selection tools. J Dairy Sci 2014;97:7889-904.

21. Calus MPL, Veerkamp RF. Estimation of environmental sensitivity of genetic merit for milk production traits using a random regression model. J Dairy Sci 2003;86:3756-64.

22. Mulder HA, Veerkamp RF, Ducro BJ, van Arendonk JAM, Bijma P. Optimization of dairy cattle breeding programs for different environments with genotype by environment interaction. J Dairy Sci 2006;89:1740-52. 